\title{
HOW TO PREPARE FOR STUDENT CLINICS
}

\author{
By Ridah Hasan
}

remember my first time on the student clinic being a daunting experience. I started

Complete Denture clinics at the beginning of my second year and had no idea of what to expect; what do I wear, what am I expected to do, how do I speak to the patients (who will be expecting me to manage their care efficiently and professionally)? Luckily I was paired up with another student (this may not be the case for many dental students) and together we managed to navigate the early days and weeks without any major mishaps. This is why I've come up with a short guide on how to manage your first time on the clinic.
Spend some time the night before and plan exactly what you need to take along with you to university the next day. And if you've followed my first tip - arriving early on clinic gives you time to pop back down to your locker in case you've forgotten something.

\section{Look the part and behave} professionally

You're going to be treating real life patients and therefore will not only be representing your university but will be representing dentistry as a profession. Think back to when you last went to the dentist - I'm sure he or she wasn't wearing a dirty tunic with open toe sandals on their feet.

Ensure you've read your hospital's dress code - iron your clinical tunic rather than shoving it in your rucksack under your laptop and anatomy textbook. Polish your shoes and tie long hair in a

\section{Arrive on time}

It's common sense but I feel like I should still clarify this. Arriving on clinic 15 minutes early is a blessing in disguise. First of all, it allows you to catch your breath if your clinic is on the 3rd floor of the dental hospital! It also allows you to familiarise yourself with the clinic and where things are. I always make sure I'm on clinic early so that I can log onto the computer, collect patient notes and labwork, read through the notes of the last appointment and plan the day's treatment.

\section{Come prepared}

Make sure you're prepared for your clinic. Whether that's remembering the right clinical book for the right clinic or just having a spare pen. During one of my restorative clinics, four of us had to share one pen because nobody had brought a spare along - not ideal. neat bun (that goes for both males and females). The GDC is increasingly strict about healthcare professionals and social media - check out the guidance from the GDC to make sure you don't fall foul of the rules. ${ }^{1,2}$

\section{Practise your speaking skills}

When talking to your patients, it's normal if you get your words muddled up so I'd suggest practising talking to a patient - whether the pretend patient is your mum on the phone or your flatmate.

Always start by introducing yourself - the 'Hello My Name Is' campaign started to teach healthcare staff how important introductions are when speaking to patients. You may have heard the quote 'you never get a second chance to make a first impression' so make sure you get off on the right foot with your patient. Speak clearly and don't use jargon - remember that your patients may not understand all of the technical words that you are familiar with in lectures; speak slowly and clearly making sure your patients understand the information you are delivering. This is especially important when you are on the Paediatric Clinic, in which case 'Childrenese' may be the language of choice.

\section{Always seek guidance from your tutor if in need}

I understand that you will want to display independence on clinic but your upmost priority as a dentist is to put the patient's best interest first; if you are unsure of anything you must ask for help. You may not be in practice yet but are still dealing with real life patients so don't embark on a procedure if you aren't $100 \%$ confident. The tutors are fully aware of your abilities and have many years of experience in supporting students fresh on the student clinics.

Finally, you're not a dentist just yet and your patients will be aware of this. As long as you conduct yourself in a professional and polite way, it's absolutely fine to say "I don't know" to a question and tell your patient that you'll ask your tutor, rather than guessing and telling them the wrong answer.

If you are still feeling nervous, I suggest you speak to a personal or clinical tutor - remember your tutors were also once students just like you and they fully know how you will be feeling.

\section{References}

1. General Dental Council. Student professionalism and fitness to practise. 2016. Online information available at https://www.gdc-uk.org/docs/default-source/ guidance-for-students/student-professionalism-andfitness-to-practise-an-introduction-for-students. pdf?sfvrsn=d34ea419_2 (Accessed June 2020).

2. Dental Defence Union. The golden rules of social media. 2018. Online information available at: https:// www.theddu.com/guidance-and-advice/guides/thegolden-rules-of-social-media (Accessed July 2020).

Ridah Hasan

https://doi.org/10.1038/s41406-020-0148-4 